\title{
A Comparison Study of Reactive Power Control Strategies in Wind Farms with SVC and STATCOM
}

\author{
Nazha Cherkaoui' ${ }^{1}$, Touria Haidi ${ }^{2}$, Abdelaziz Belfqih ${ }^{3}$, Faissal El Mariami ${ }^{4}$, Jamal Boukherouaa $^{5}$ \\ 1,3,4, 5 Laboratory of Electrical Systems and Energy, National Higher School of Electricity \\ and Mechanics (ENSEM), Morocco \\ ${ }^{2}$ Laboratory of Electrical Systems, Hassania School of Public Works (EHTP), Morocco
}

\begin{tabular}{l} 
Article Info \\
\hline Article history: \\
Received Mar 24, 2018 \\
Revised Jun 14, 2018 \\
Accepted Jul 22, 2018 \\
\hline Keyword: \\
Doubly fed induction generator \\
Point of common coupling \\
Reactive power control \\
strategies \\
STATCOM \\
SVC \\
Wind power plant
\end{tabular}

Wind power plant

\begin{abstract}
In the recent years, the integration of the wind farms into the electrical grids has increased rapidly. Especially, the wind power plants made up with doubly fed induction generators due to its many advatanges, such as being able to control its reactive power. Hence, some countries have published grid code requirements related to the reactive power that the wind turbines have to satisfy. This paper presents a coordinated reactive power control strategy in which STATCOM and doubly fed induction generators in wind power plants are used in order to bring back the voltage at the point of common coupling in the allowable range. First, reactive power requirements that the wind farms have to fulfill in some European countries are introduced. Second, the reactive power limitations of $2 \mathrm{MW}$ doubly fed induction generator are determined. Then, the static synchronous compensator (STATCOM) and the synchronous var compensator (SVC) FACTS (Flexible AC Transmission Systems) devices are presented. Finaly, various reactive power control strategies are applied to $10 \mathrm{MW}$ wind farm, and the simulation results are analysed and compared.
\end{abstract}

Copyright $@ 2018$ Institute of Advanced Engineering and Science. All rights reserved.

\section{Corresponding Author:}

Nazha Cherkaoui,

Laboratory of Electrical Systems and Energy,

National Higher School of Electricity and Mechanics,

El Jadida Road, km 7, Casablanca, Morocco.

Email: nazha.cherkaoui@ensem.ac.ma

\section{INTRODUCTION}

In recent years, the integration of renewable energies into the power grids has increased significantly. Among the renewable sources available, the wind turbine is the most installed in the world because it is clean and cheap. Transmission system operators (TSO) in several countries require the wind power plants (WPP) to be able to contribute to ancillary services, for instance voltage regulation and reactive power control. Moreover, in some countries such as China when the reactive power capacity of a wind turbine cannot meet the system voltage regulation requirements, a reactive compensation device with proper capacity shall be installed at the WPP; if necessary, a dynamic reactive compensation device shall be installed [1].

Many works have been done in order to discuss various strategies in which wind farms take part in the voltage regulation in order to maintain the voltage in the electrical network within the allowable range [2]-[3]. However, the reactive power capability of small wind farms is not sufficient to bring back the voltage at the point of common coupling (PCC) in the acceptable range when a deep voltage sag occurs in the grid. Hence, there is a need in such cases to install reactive compensation devices. In literature, some studies have presented reactive power compensation strategies in which FACTS devices are used. For example, the authors in [4] show that the connection of the STATCOM at the PCC can contribute to mitigate voltage 
fluctuation in electrical networks to which a wind farm is connected. Besides, in [5], the implementation of the STATCOM on a wind farm based DFIG participate to mitigate voltage sag in the power system. Nevertheless, the wind power plants can also contribute in voltage regulation if specific technologies of wind turbines are installed; therefore, wind turbines can be used as reactive power compensators if the reactive power provided by the reactive compensation devices is insufficient. In this paper, first, a comparative analysis is done between the most FACTS devices used for voltage regulation, namely the SVC and the STATCOM. Then, a coordinated reactive power control strategy is proposed. In this strategy, the STATCOM and DFIGs based WF are used to take back the voltage to the admissible value.

This paper is organized as follows: first, grid code requirements related to the reactive power capability of wind turbines in some European countries are introduced. Second, the method proposed in [6] is used to obtain the reactive power capability of a DFIG WT with a capacity of $2 \mathrm{MW}$. Then, the synchronous var compensator (SVC) and the static synchronous compensator (STATCOM) devices are presented. Finally, a comparative analysis between three reactive power control strategies so that to keep the voltage in the acceptable range is done.

\section{GRID CODE REQUIREMENTS RELATED TO THE REACTIVE POWER CAPABILITY OF WIND FARMS}

In many countries, the wind power plants (WPP) are required to have the capability to contribute to voltage regulation so that to maintain the voltage in the electrical network within an allowable range. Hence, the wind turbines in the WF have to be able to supply or absorb reactive power in order to support the voltage at the PCC during voltage variations on the power system.

Figure 1 shows reactive power capability requirements of various European grid codes. If a wind turbine or a wind farm operates with the whole area illustrated in Figure 2, so all European grid code requirements related to reactive power capability can be satisfied.

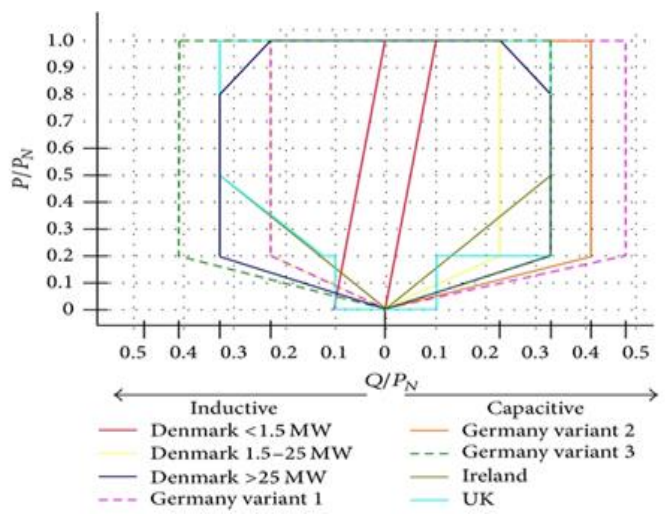

Figure 1. Reactive power capability requirements in many European grid codes [6]

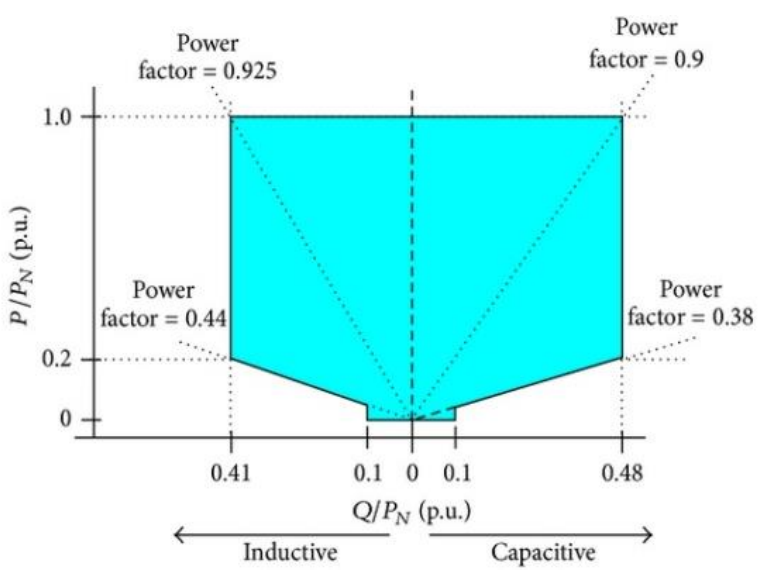

Figure 2. P-Q profile to satisfy all European grid codes [6] 


\section{DOUBLY FED INDUCTION GENERATOR}

As shown in Figure 3, the DFIG consists of a turbine, an induction generator and a back to back converter. The DFIG wind turbine supplies the major quantity of electric power into the network through the stator, while only a fraction of the power is passed through the converter from the rotor [7]. The DFIG has several advantages, therefore; it is the most commonly used technology in the world. In fact, the rotor side converter allows controlling the rotor currents to obtain the desired active and reactive powers at the stator side [8]. Besides, the DFIG is the cheapest solution to ensure variable speed operation because its converts are sized only for about $30 \%$ of the nominal generated power [9].

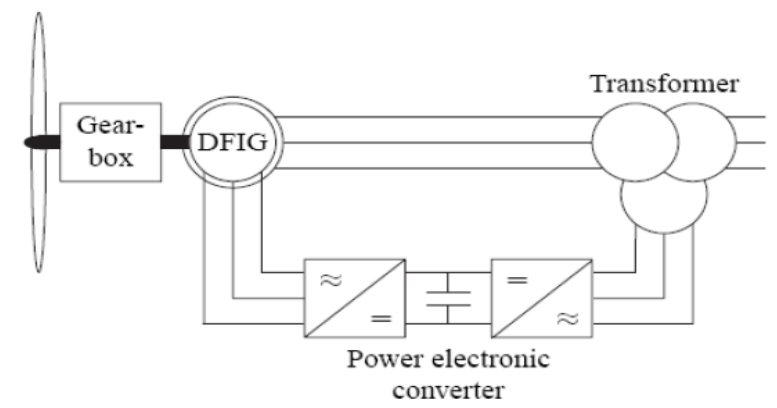

Figure 3. The basic layout of a DFIG wind turbine [10]

\section{REACTIVE POWER CAPABILITY OF DFIG WIND TURBINE}

The P-Q diagram proposed in [7] is used to get the reactive power capability of 2 MW DFIG. In this method, it is suggested that the reactive power capability is limited by three parameters: rotor current $\left(\mathrm{I}_{\mathrm{r}}\right)$, stator current $\left(\mathrm{I}_{\mathrm{s}}\right)$ and rotor voltage $\left(\mathrm{V}_{\mathrm{r}}\right)$. The complex powers from the stator and the rotor windings are derived using the steady state T- equivalent circuit shown in Figure 4, also; it is considered that the stator voltage is equal to 1 p.u. As illustrated in Figure 5, the PQ diagram of 2 MW DFIG is obtained by the most restrictive of the three boundaries. The parameters used in this paper are shown in Table 1.

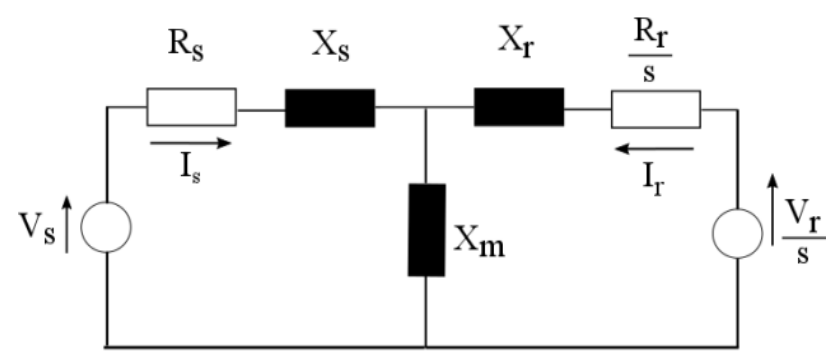

Figure 4. Steady state T-equivalent circuit of the DFIG

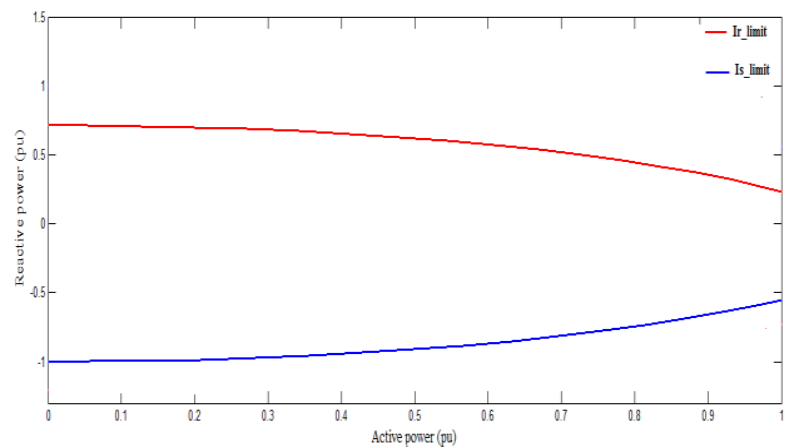

Figure 5. PQ diagram of the DFIG used in this paper 
Table 1. REpower MM82 parameters [11]

\begin{tabular}{lc}
\hline \multicolumn{1}{c}{ Machine parameter } & Value \\
\hline Nominal active power & $2 \mathrm{MW}$ \\
Nominal stator voltage & $690 \mathrm{~V}$ \\
Stator resistance & $0.00206 \Omega$ \\
Stator inductance & $0.032 \Omega$ \\
Rotor resistance & $0.0028 \Omega$ \\
Rotor inductance & $0.021 \Omega$ \\
Magnetizing resistance & $36.4 \Omega$ \\
Magnetizing inductance & $0.83 \Omega$ \\
Turn ratio & 2.43 \\
Slip & -0.2 \\
\hline
\end{tabular}

\section{SVC (Static VAR Compensator) [12]-[14]}

The SVC is a FACTS (Flexible AC Transmission Systems) device that allows improving transient stability and controlling power flow in electrical networks. The SVC adjusts the voltage on power systems by absorbing or supplying reactive power at the point of connection. In fact, the SVC provides reactive power when network voltage is low, and it consumes reactive power when network voltage is high.

The SVC, as shown in Figure 6 consists of a combination of Thyristor switched capacitor (TSC) and Thyristor controlled reactor (TCR) connected in parallel with electrical network. The reactor and the capacitor banks connected on the secondary side of a coupling transformer are switched to obtain the necessary reactive power in order to keep the voltage in the desired value.

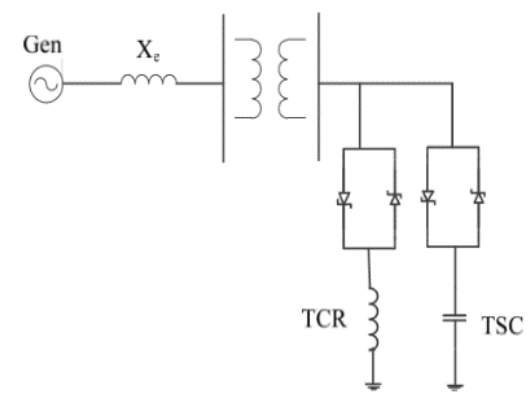

Figure 6. Static Var Compensator (SVC)

The SVC operates in voltage regulation mode and in var control mode. In var control mode, the susceptance of SVC is kept constant. The V-I characteristic shown in Figure 7 is implemented when the SVC operates in the voltage regulation mode:

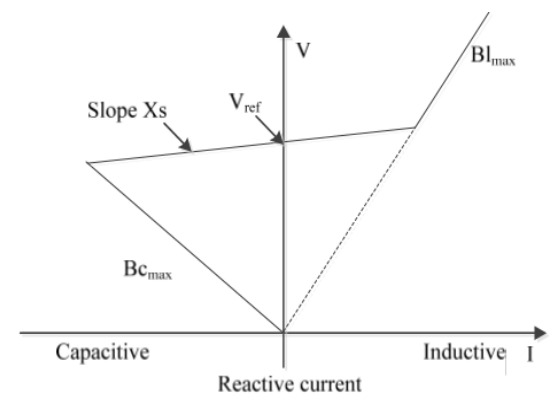

Figure 7. SVC V-I characteristic

The voltage is adjusted to the reference voltage $V_{\text {ref }}$ so long as the susceptance $B$ of the SVC remains within the bounds values (minimum and maximum susceptance values). These limits values are imposed by the sum of the reactive power of reactor $\left(B_{\operatorname{lmax}}\right)$ and capacitor banks $\left(\mathrm{B}_{\mathrm{cmax}}\right)$. The equations bellow describe the V-I characteristic: 


$$
\begin{array}{ll}
V=V_{\text {ref }}+X_{S} \cdot I & \text { When SVC operates in regulation mode }\left(-B_{c \max }<B<B_{l m a x}\right) \\
V=-\frac{I}{B_{\text {cmax }}} & \text { When SVC is entirely capacitive }\left(B=B_{c \max }\right) \\
V=\frac{I}{B_{l \max }} & \text { When SVC is entirely inductive }\left(B=B_{\text {lmax }}\right)
\end{array}
$$

Where

$\mathrm{V} \quad$ : Positive sequence voltage $(\mathrm{pu})$

I : Reactive current $\left(\mathrm{pu} / \mathrm{P}_{\text {base }}\right)$

$\mathrm{X}_{\mathrm{s}} \quad$ : Slope or droop reactance $\left(\mathrm{pu} / \mathrm{P}_{\mathrm{base}}\right)$

$\mathrm{B}_{\mathrm{cmax}}$ : Maximum capacitive susceptance when only all TSCs are in service $\left(\mathrm{pu} / \mathrm{P}_{\mathrm{base}}\right)$

$\mathrm{B}_{\text {lmax }}$ : Maximum inductive susceptance when only all TCR are in service $\left(\mathrm{pu} / \mathrm{P}_{\mathrm{base}}\right)$

$\mathrm{P}_{\text {base }}:$ Three phase base power

\section{STATIC SYNCHRONOUS COMPENSATER (STATCOM) [14], [15]}

The STATCOM is a FACTS device that permits improving power factor and regulating the network voltage by injecting or consuming reactive power to or from the power grid. Figure 8 illustrates the principle of operation of STATCOM. A voltage Source Converter (VSC) which is connected on the secondary side of a coupling transformer allows getting the necessary reactive power. The VSC utilizes a forced commutated power electronics device (IGBTs, GTOs) to get a voltage U2 from a DC voltage source.
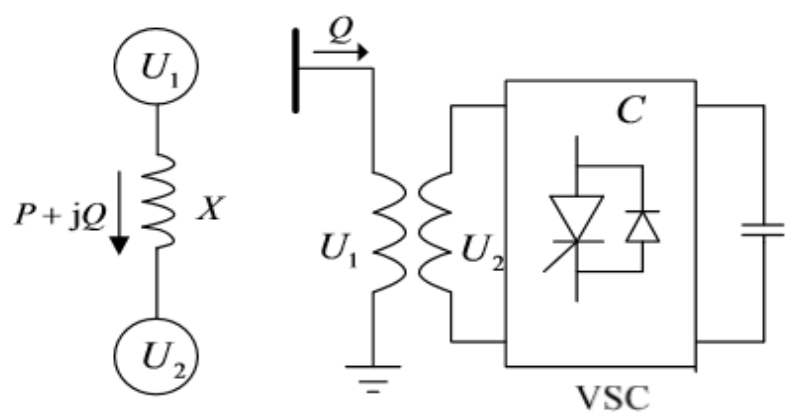

Figure 8. Static Synchronous Compensator (STATCOM)

The active and reactive power output of the STATCOM are given by equations (4) and (5):

$$
\begin{aligned}
& P=\frac{\mathrm{U}_{1} \mathrm{U}_{2} \sin \delta}{\mathrm{X}} \\
& \mathrm{Q}=\frac{\mathrm{U}_{1}\left(\mathrm{U}_{1}-\mathrm{U}_{2} \cos \delta\right)}{\mathrm{X}}
\end{aligned}
$$

Where

$\mathrm{U}_{1} \quad$ : The voltage value of the controlled system

$\mathrm{U}_{2} \quad$ : The output voltage value of the VSC

$\delta \quad:$ The difference of the phase angle between $\mathrm{U}_{1}$ and $\mathrm{U}_{2}$

$\mathrm{X} \quad$ : Reactance of filters and interconnection transformer

In the steady state, $\delta$ is equal to $0\left(\mathrm{U}_{2}\right.$ is in phase with $\left.\mathrm{U}_{1}\right)$, so only the reactive power flow $(\mathrm{P}=0)$. To ensure a dynamic reactive power regulation, the VSC controls the magnitude of $\mathrm{U}_{2}$ in order to control the voltage difference between $U_{2}$ and $U_{1}$. Therefore, the STATCOM is able to adjust grid voltage $U_{1}$ by providing or absorbing reactive power.

The STATCOM operates in voltage regulation mode and var control mode. In var control mode, the reactive power output is maintained constant. Figure 9 shows the V-I characteristic implemented when the STATCOM operates in voltage regulation mode. 


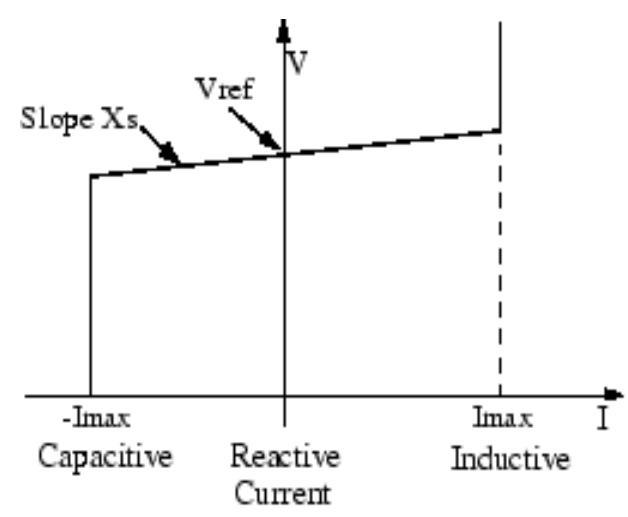

Figure 9. STATCOM V-I characteristic

The voltage is adjusted to the reference voltage $V_{\text {ref }}$ so long as the reactive currents remain within the current limits $\left(-I_{\max }, I_{\max }\right)$ which are imposed by the converter rating. The V-I characteristic of the STATCOM is obtained by the equation (6):

$$
\mathrm{V}=\mathrm{V}_{\text {ref }}+\mathrm{X}_{\mathrm{s}} \cdot \mathrm{I}
$$

Where

$\mathrm{V} \quad$ : Positive sequence voltage

$\mathrm{X}_{\mathrm{s}} \quad$ : Slope

I : Reactive current

\section{REACTIVE POWER CONTROL STRATEGY OF WPP BASED DFIG WIND TURBINE [16]}

The purpose of the strategy presented in this paragraph is to obtain the reactive power reference of each WT in the WF in order to produce the necessary reactive power so that to keep the voltage in the electrical grid in the admissible range required by the TSO. This strategy is explained in steps as:

- Step 1. The reactive power limits of each DFIG $\left(Q_{i}^{\max }\right.$ and $\left.Q_{i}^{\min }\right)$ are obtained using the method presented in paragraph IV.

- Step 2. The voltage measured at the PCC is compared with the voltage required by the TSO.

- Step 3. The proportional voltage control block diagram [17] illustrated in Figure 10 is utilized to calculate the reactive power required by the WF $Q_{W F}^{s e t}$

- Step 4. If $Q_{W F}^{s e t}<Q_{W F}^{\max }=\sum_{i=1}^{n} Q_{i}^{\max }$, then the minimum number $n_{\min }$ of the WTs that contribute in the reactive power support is determined according to the reactive power limitations of each WT $Q_{i}^{\max }$. The number $n_{\min }$ is chosen until $\sum_{i=1}^{n_{\min }} Q_{i}^{\max } \geq Q_{W F}^{\text {set }}$ is met.

If $Q_{W F}^{s e t} \geq Q_{W F}^{\max }$, then all the DFIGs will participate in the voltage regulation.

- Step 5. When finished, return to step1.

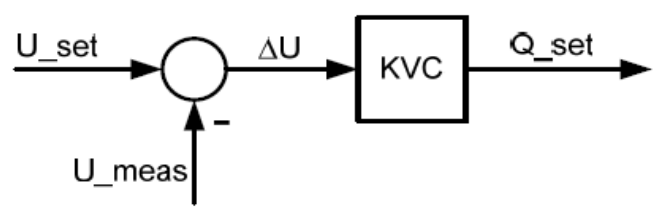

Figure 10. Proportional voltage control block diagram [17]

\section{SIMULATION RESULTS}

The purpose of this work is to present a coordinated reactive power control strategy in which the STATCOM and the wind farm made up with DFIG wind turbines are utilized. First, a comparative analysis between the SVC and the STATCOM is done in order to choose the appropriate FACTS device to use in the proposed strategy. Then, a comparison is done between the results obtained with the proposed strategy and

A Comparison Study of Reactive Power Control Strategies in Wind Farms with SVC ... (Nazha Cherkaoui) 
when only FACTS devices are used for voltage regulation. To do this, an 85 Mvar new load has been added to the test network, as illustrated in Figure11; therefore, a voltage sag occurs at all buses in the network. As shown in Figure 11, the wind power plant consists of five 2 MW DFIG, and it is connected to a 20-kV distribution power system that exports power to $63 \mathrm{kV}$ network through a $10 \mathrm{~km} 20 \mathrm{kV}$ feeder.

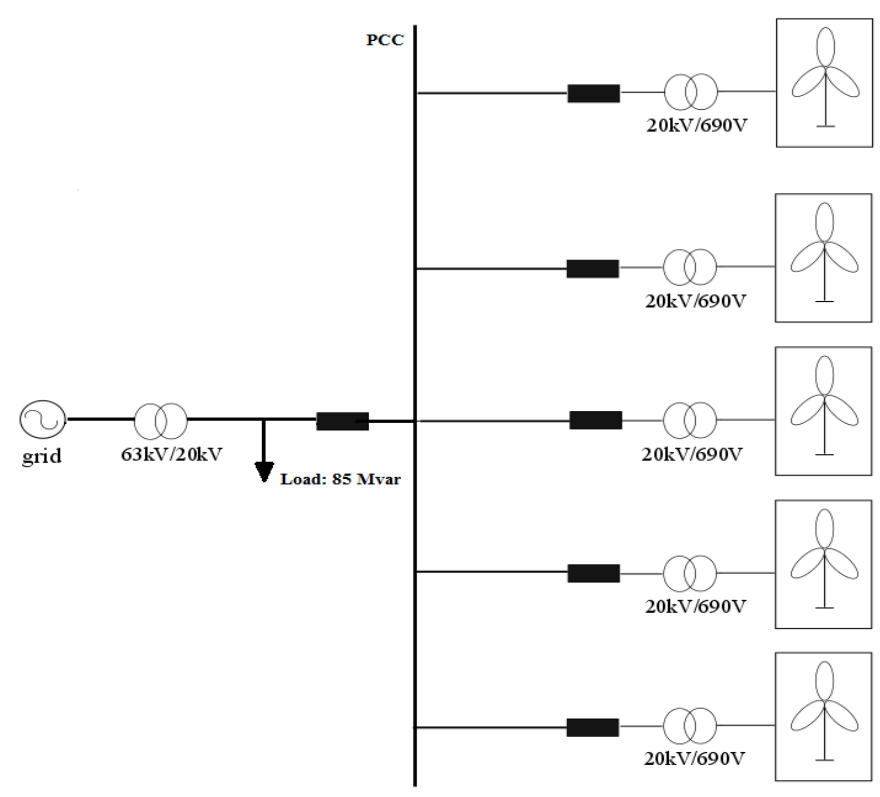

Figure 11. An exemple case for simulation $13 \mathrm{~m} / \mathrm{s}$ :

Four cases are tested and compared. In every case the wind speed is considered to be equal to

- Case 1: There is no reactive power control strategy applied in this case.

- Case 2: A 15 Mvar SVC is the only element in the wind farm that provides reactive power, while the reactive power reference sent to each WT within the WPP is equal to 0 .

- Case 3: A 15 Mvar STATCOM is the only element in the wind farm that generates reactive power, while the reactive power reference sent to each WT within the WPP is equal to 0 .

- Case 4: The DFIG wind turbines within the WF provide reactive power using the strategy presented in paragraph VII when the STATCOM reaches a certain value of its capacity. In this work, this value is considered to be equal to $90 \%$ of the STATCOM's capacity.

The factor of voltage control block $\mathrm{k}_{\mathrm{V}_{\mathrm{C}}}$ is calculated as follow:

$$
\mathrm{k}_{\mathrm{V}_{\mathrm{C}}}=\frac{\mathrm{Q}_{\text {max }}^{\mathrm{i}}-\mathrm{Q}_{\text {min }}^{\mathrm{i}}}{\Delta \mathrm{U}}
$$

where $\mathrm{Q}_{\text {max }}^{\mathrm{i}}$ and $\mathrm{Q}_{\text {min }}^{\mathrm{i}}$ are the maximum reactive power production/absorption required in order to fulfil all European grid codes, and $\Delta \mathrm{U}$ is the range around the rated value, which is set to $0.1 \mathrm{pu}$ in this work.

The simulation results are illustrated in Figure 12, 13, 14, and 15. As we can notice from Figure 12, the active power decreases significantly in the first case when no reactive power control strategy is applied, whereas it stayed almost the same in the other cases. 

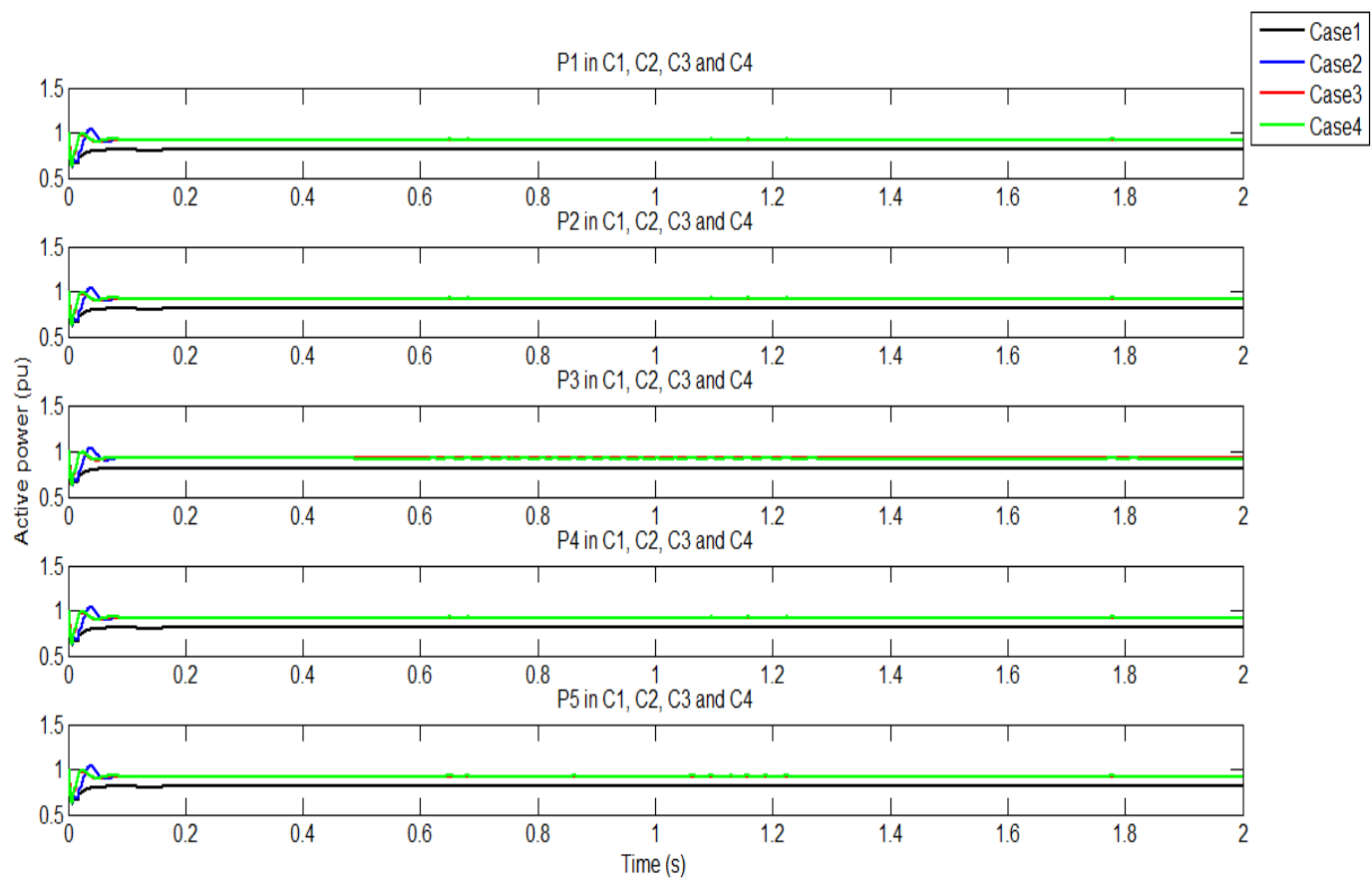

Figure 12. Active power outputs by the WTs 1, 2, 3, 4 and 5

As shown in Figure 13, the reactive power outputs by the WTs within the WPP is equal to 0 in case 1, 2 and 3. This is due to the fact that the WF don't contribute to voltage regulation in these cases. However, the WF participate to voltage regulation in case 4. Furthermore, the reactive power output by the WT 5 is almost equal to 0 from the time $0,4 \mathrm{~s}$ because the reactive power supplied by the remained WTs in the WPP is sufficient to take part in reactive power support.

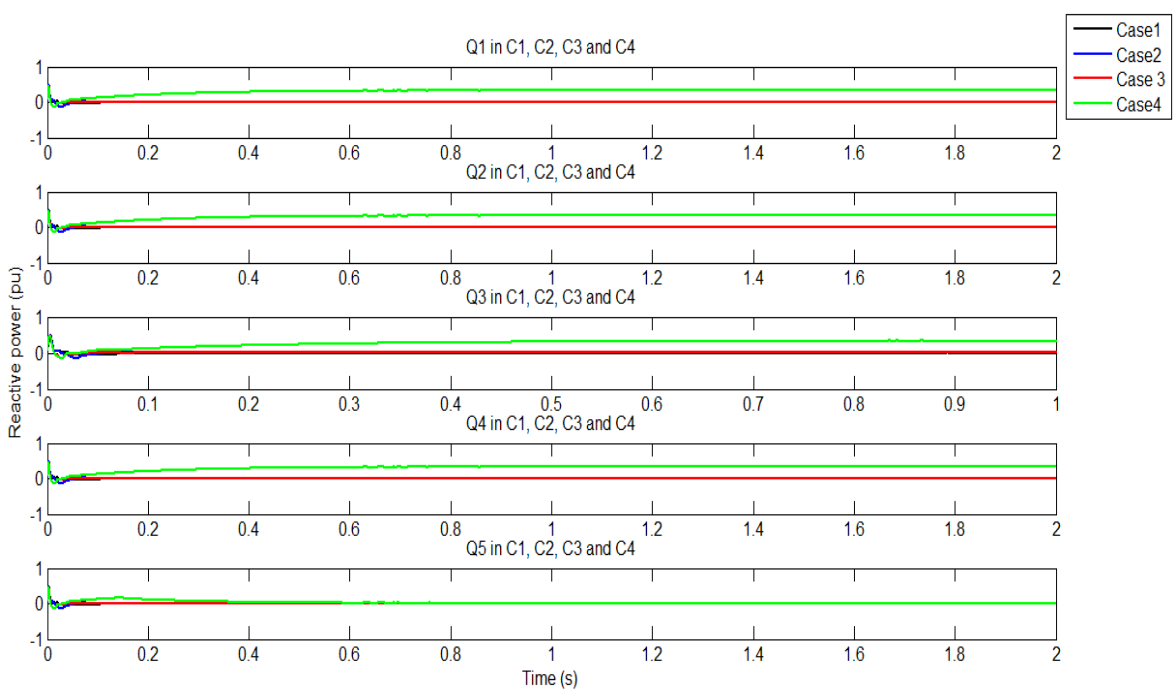

Figure 13. Reactive power outputs by the WTs 1, 2, 3, 4 and 5

As illustrated in Figure 14, the addition of a new load of 85 Mvar to the grid causes a drop voltage at the PCC. The implementation of FACTS devices at the PCC helps to increase the voltage at this point from $0,735 \mathrm{pu}$ in case 1 to $0,9325 \mathrm{pu}$ in case 2 and to $0,9461 \mathrm{pu}$ in case 3 . This is due to the fact that the reactive power provided by the STATCOM is bigger than that provided by the SVC, as shown in Figure 15, although the fact that they have the same rating. As a result, we can conclude that the STATCOM gives better 
performance in comparison to the SVC. However, the significant improvement in the voltage at the PCC is obtained in case 4 because this is when the most important amount of reactive power is injected. We can conclude that the proposed strategy permits getting the best results.

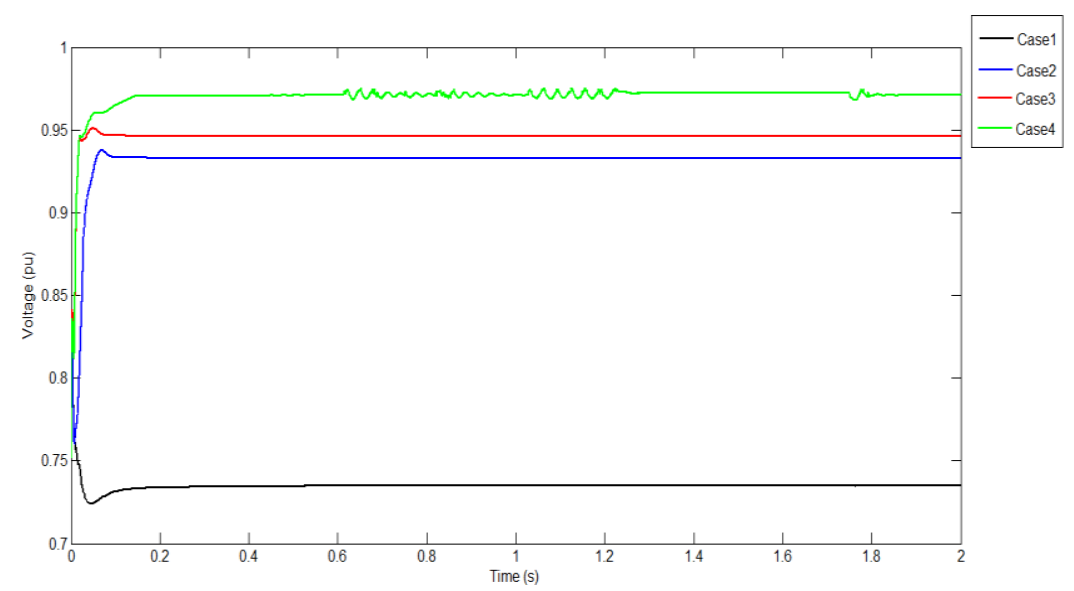

Figure 14. Voltage at the PCC in case 1, 2, 3 and 4

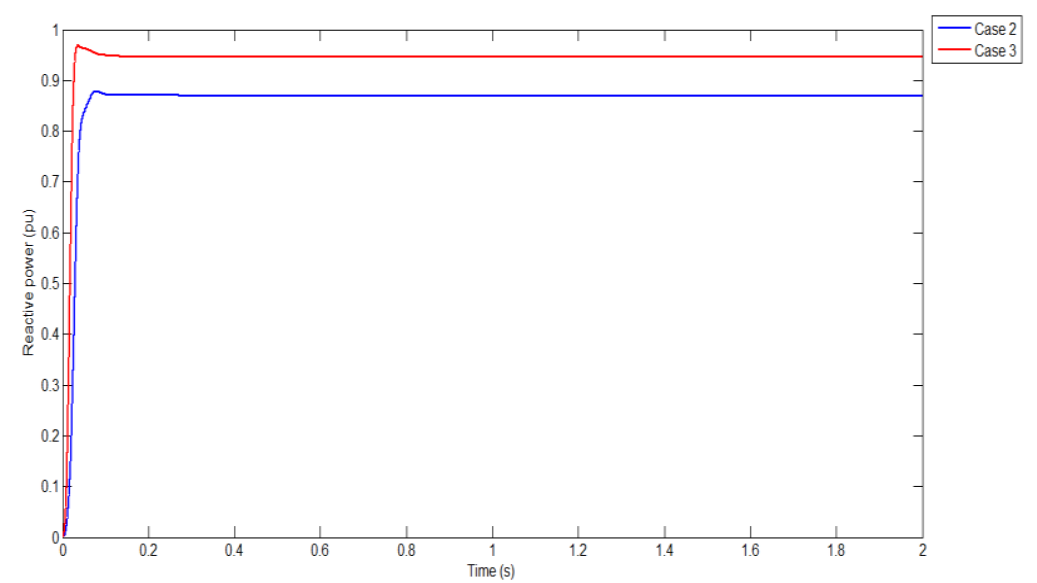

Figure 15. Reactive power outputs by the SVC and the STATCOM

\section{CONCLUSION}

In this work, we present a coordinated reactive power control strategy in which the doubly fed induction generators in the wind power plant and a STATCOM are used so that to maintain the voltage at the point of common coupling in the acceptable range. To validate the performance of the proposed strategy, it was compared with other reactive power control strategies in which two differents FACTS technologies are used for voltage regulation. Simulation results show that the significant improvement of the voltage at the point of common coupling is obtained when the wind farm takes part in the reactive power support in addition to the STATCOM.

\section{REFERENCES}

[1] W. Gao, et al., "Comparison of standards and technical requirements of grid-connected wind power plants in China and the United States," 2016. Available at www.nrel.gov/publications.

[2] J. Zhai and H. Liu, "Reactive power control strategy of DFIG wind farms for regulating voltage of power grid," IEEE PES General Meeting, Conference \& Exposition, 2014.

[3] J. Kim, et al., "Adaptive Q-V scheme for the voltage control of a DFIG-based wind power plant," IEEE Trans. Power Electron, vol/issue: 31(5), 2016. 
[4] M. A. Tofigh, et al., "Voltage regulation of grid connected wind farm using STATCOM," Power and Energy Engineering Conference (APPEEC), Asia-Pacific, 2010.

[5] M. J. Ghorbanian, et al., "Mitigating voltage sag by implementing STATCOM on DFIG-based wind farms connected to a power system," 4th International Conference on Engineering Technology and Technopreneuship (ICE2T), Kuala Lumpur, Malaysia, 2014

[6] C. Sourkounis and P. Tourou, "Grid code requirements for wind power integration in Europe," Conference Papers in Energy, 2013.

[7] T. Lund, et al., "Reactive power capability of a wind turbine with doubly fed induction generator," Wind Energy, vol. 10, pp. 379-394, 2007.

[8] P. Vijayan, "Utilizing reactive capability of doubly fed induction generators to enhance system voltage performance and withstand wind variability," master thesis, 2010.

[9] A. M. Thin and N. S. Y. Kyaing, "Performance analysis of doubly fed induction generator using vector control technique," International Journal of Electrical and Computer Engineering (IJECE), vol/issue: 5(5), pp. 929-938, 2015.

[10] S. J. Basha and L. R. Burthi, "Application of power matrix technique for controlling DFIG wind turbine system," TELKOMNIKA Indonesian Journal of Electrical Engineering, vol/issue: 16(2), pp. 265-271, 2015.

[11] A. Ahmidi, "Wind farms participation at voltage and reactive power regulation in the power system network," Phd dissertation, 2010.

[12] S. G. Farkoush, et al., "Efficient Power factor improvement with SVC based on the PI controller under Load Fault in the smart gri," International Journal of Applied Engineering Research, vol/issue: 11(1), pp. 96-100, 2016.

[13] S. A. Jumaat, et al., "A voltage improvement of transmission system using static var compensator via Matlab/Simulink," Indonesian Journal of Electrical Engineering and Computer Science (IJEECS), vol/issue: 6(2), pp. $330-337,2017$.

[14] Available at www.mathworks.com

[15] H. Li, et al., "Study of STATCOM on Reactive Power Compensation Strategy of Wind Farm," International Conference on Computer Sciences and Applications, Wuhan, China, 2013.

[16] N. Cherkaoui, et al., "Voltage regulation in the electrical network using reactive power control strategy of WPP based DFIG wind turbine," 3rd Irnternational Conference on Electrical and Information Technologies ICEIT'2017, Rabat, Morocco, 2017.

[17] R. Bluhm and J. Fortmann, "Advanced two-level voltage control in wind farms with Doubly Fed Induction Generators," European Wind Energy Conference, Warsaw, Poland, 2010. 


\section{BIOGRAPHIES OF AUTHORS}
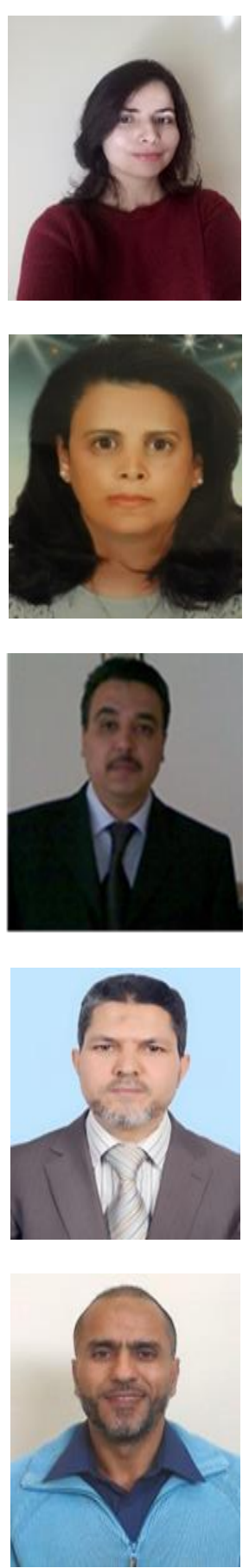

Nazha Cherkaoui is a Ph.D. student at the National Higher School of Electricity and Mechanics (University Hassan II of Casablanca - Morocco). Her research interests include renewable energies and power systemes.
Touria Haidi is a research professor at Hassania School of Public Works (EHTP) in Casablanca, Morocco. She holds an Engineer's degree in Electrotechnics and Power Electronics from EHTP. She also holds an in-depth studies Certificate in Information Processing from the University of Ben M'sick, Casablanca and specialised Master in Information Systems and Processing. She is a member of the EHTP "Automatic, Electrical Systems and Renewable Energies" research team. She currently works on the integration of renewable energies in electrical networks.

Abdelaziz Belfqih is a professor at the National High School of Electricity and Mechanics (University Hassan II of Casablanca - Morocco). PhD, Engineer and holder of the University Habilitation searches (HDR). Head of the research team "Electrical Networks and Static Converters." Teacher researcher currently working on electricity network and smart grids.

Faissal El Mariam is a professor at the Superior National High School of Electricity and Mechanics (University Hassan II of Casablanca - Morocco). PhD, Engineer and holder of the University Habilitation searches (HDR). Head of the research team "Electrical Networks and Static Converters." Teacher researcher currently working on stability of the electricity network and smart grids.

Jamal Boukherouaa is a professor at the National High School of Electricity and Mechanics (University Hassan II of Casablanca Morocco). PhD, Engineer and holder of the University Habilitation searches (HDR). Head of the research team "Electrical Networks and Static Converters." Teacher researcher currently working on high frequency static converters. 